\title{
1. Overview of theories, models and frameworks in implementation science Per Nilsen
}

\section{INTRODUCTION}

Early implementation research tended to be empirically driven. For example, a review of guideline implementation strategies by Davies et al. (2003) noted that only 10 per cent of the studies identified provided an explicit rationale for their strategies. Eccles et al. (2005, p. 108) remarked that research that did not use theories seemed like 'an expensive version of trial-and-error'. Mixed results of implementing evidence-based practice (EBP) in various settings were often attributed to a limited theoretical basis (Davies et al., 2003; Eccles et al., 2005; Kitson et al., 1998; Michie et al., 2005; Sales et al., 2006). Poor theoretical underpinning makes it difficult to understand and explain how and why implementation succeeds or fails, thus restraining opportunities to identify factors that predict the likelihood of implementation success.

Although the use of theories, models and frameworks today has many advocates in implementation science, there have been dissenting voices. In a light-hearted (but still fairly serious) article, Oxman et al. (2005, p. 113) presented their OFF Theory, which they summarized as: 'you don't need a theory' (OFF stands for Oxman, Fretheim, Flottorp). They were critical of theory use in implementation science, and argued that, 'We need less rather than more focus on high-level theories, less rather than more jargon, less dogmatism, more common sense, less theoretical work, and more rigorous evaluations that include direct measurement of important outcomes' (Oxman et al., 2005, p.115). Still, over time implementation science has increasingly emphasized the importance of establishing the theoretical bases of implementation and strategies to facilitate implementation. In fact, there are now so many theoretical approaches that some researchers have complained about the difficulties of choosing the most appropriate (Cane et al., 2012; Godin et al., 2008; ICEBeRG, 2006; Martinez et al., 2014; Mitchell et al., 2010; Rycroft-Malone and Bucknall, 2010a).

This chapter provides a narrative review of the theories, models and frameworks applied in this research field. The aim is to describe and 
analyse how theories, models and frameworks have been applied in implementation science and to propose a taxonomy that distinguishes between different approaches to advance clarity and achieve a common terminology. The ambition is to facilitate appropriate selection and application of relevant approaches in implementation studies and to foster cross-disciplinary dialogue among implementation researchers. The importance of a clarifying taxonomy has evolved during the many discussions on theoretical approaches used within implementation science that the author has had over the past few years with fellow implementation researchers, as well as reflection on the utility of different approaches in various situations.

Six textbooks that provide comprehensive overviews of research regarding implementation science and implementation of EBP were consulted: Rycroft-Malone and Bucknall (2010c), Nutley et al. (2007), Greenhalgh et al. (2005), Grol et al. (2005), Straus et al. (2009) and Brownson et al. (2012). A few papers presenting overviews of theories, models and frameworks used in implementation science were also used: Estabrooks et al. (2006), Sales et al. (2006), Graham and Tetroe (2007), Mitchell et al. (2010), Flottorp et al. (2013), Meyers et al. (2012) and Tabak et al. (2012). In addition, Implementation Science was searched using the terms 'theory', 'model' and 'framework' to identify relevant articles. The titles and abstracts of the identified articles were scanned, and those that were relevant to the study aim were read in full.

\section{THEORIES, MODELS AND FRAMEWORKS IN THE GENERAL LITERATURE AND IN IMPLEMENTATION SCIENCE}

Generally, a theory may be defined as a set of analytical principles or statements designed to structure our observation, understanding and explanation of the world (Carpiano, 2006; Frankfort-Nachmias and Nachmias, 1996; Wacker, 1998). Authors usually point to a theory as being made up of definitions of variables, a domain where the theory applies, a set of relationships between the variables and specific predictions (Bunge, 1967; Dubin, 1969; Hunt, 1991; Reynolds, 1971). A 'good theory' provides a clear explanation of how and why specific relationships lead to specific events. Theories can be described on an abstraction continuum. High abstraction level theories (general or grand theories) have an almost unlimited scope, middle abstraction level theories explain limited sets of phenomena, and lower level abstraction theories are empirical generalizations of limited scope and application (Bluedorn and Evered, 1980; Wacker, 1998). 
A model typically involves a deliberate simplification of a phenomenon or a specific aspect of a phenomenon. Models need not be completely accurate representations of reality to have value (Carpiano, 2006; Cairney, 2012). Models are closely related to theory and the difference between a theory and a model is not always clear. Models can be described as theories with a more narrowly defined scope of explanation; a model is descriptive, whereas a theory is explanatory as well as descriptive (Frankfort-Nachmias and Nachmias, 1996).

A framework usually denotes a structure, overview, outline, system or plan consisting of various descriptive categories - for example, concepts, constructs or variables - and the relations between them that are presumed to account for a phenomenon (Sabatier, 1999). Frameworks do not provide explanations; they only describe empirical phenomena by fitting them into a set of categories (Frankfort-Nachmias and Nachmias, 1996).

With regard to implementation science, the terms 'theories', 'models' and 'frameworks' are often used interchangeably (Estabrooks et al., 2006; Kitson et al., 2008; Rycroft-Malone and Bucknall, 2010a). A theory in this field usually implies some predictive capacity (for example, to what extent do health care practitioners' attitudes and beliefs concerning a clinical guideline predict their adherence to this guideline in clinical practice?) and attempts to explain the causal mechanisms of implementation. Models in implementation science are commonly used to describe and/or guide the process of translating research into practice (that is, 'implementation practice') rather than to predict or analyse what factors influence implementation outcomes (that is, 'implementation research'). Frameworks in implementation science often have a descriptive purpose by pointing to factors believed or found to influence implementation outcomes (for example, health care practitioners' adoption of an evidence-based patient intervention). Neither models nor frameworks specify the mechanisms of change; they are typically more like checklists of factors relevant to various aspects of implementation.

It is possible to identify three overarching aims of the use of theories, models and frameworks in implementation science:

- describing and/or guiding the process of translating research into practice;

- understanding and/or explaining what influences implementation outcomes;

- evaluating implementation.

Based on descriptions of their origins, how they were developed, what knowledge sources they drew on, stated aims and applications in 


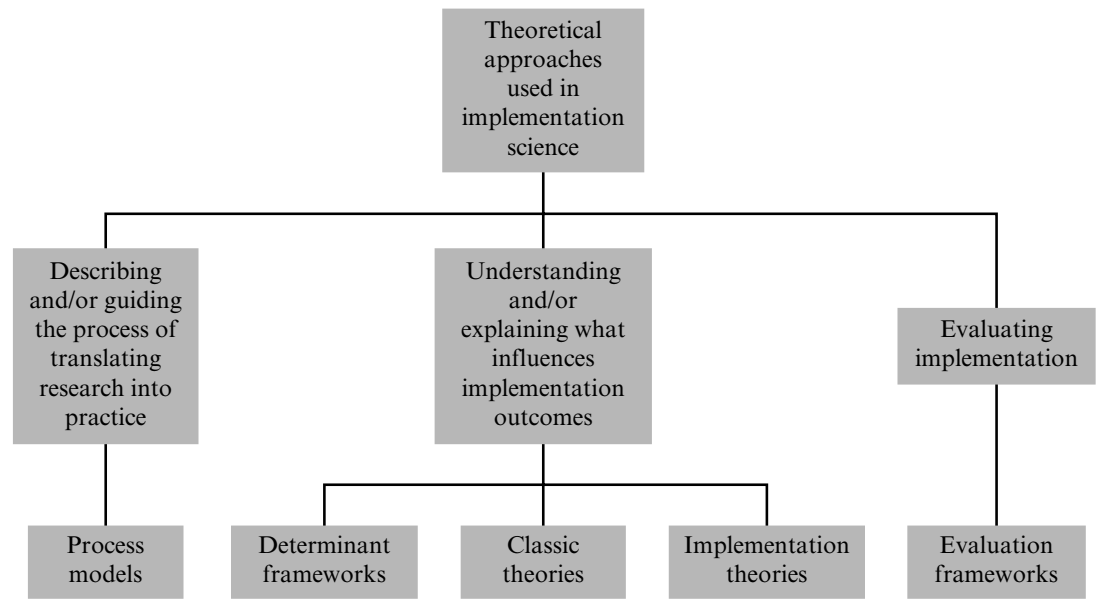

Figure 1.1 Three aims of the use of theoretical approaches in implementation science and the five categories of theories, models and frameworks

implementation science, theoretical approaches that aim at understanding and/or explaining influences on implementation outcomes (that is, the second aim) can be further broken down into:

- determinant frameworks;

- classic theories;

- implementation theories.

Thus, five categories of theoretical approaches used in implementation science can be delineated, as shown in Figure 1.1. Table 1.1 summarizes the five categories and provides examples of approaches in each category.

\section{PROCESS MODELS}

Process models are used to describe and/or guide the process of translating research into practice. Models by Huberman (1994), Landry et al. (2001), the CIHR (Canadian Institutes of Health Research, 2014), the Knowledge Model of Knowledge Translation, Davis et al. (2007), Majdzadeh et al. (2008) and the K2A (Knowledge-to-Action) Framework, Wilson et al. (2011) outline phases or stages of the research-to-practice process, from discovery and production of research-based knowledge to implementation and use of research in various settings. 
Table 1.1 Five categories of theories, models and frameworks used in implementation science

\begin{tabular}{|c|c|c|}
\hline Category & Description & Examples \\
\hline rocess models & $\begin{array}{l}\text { Specify steps (stages, } \\
\text { phases) in the process } \\
\text { of translating research } \\
\text { into practice, including } \\
\text { the implementation and } \\
\text { use of research. The aim } \\
\text { of process models is to } \\
\text { describe and/or guide the } \\
\text { process of translating } \\
\text { research into practice. An } \\
\text { action model is a type of } \\
\text { process model that provides } \\
\text { practical guidance in the } \\
\text { planning and execution of } \\
\text { implementation endeavours } \\
\text { and/or implementation } \\
\text { strategies to facilitate } \\
\text { implementation. Note } \\
\text { that the terms 'model' and } \\
\text { 'framework' are both used, } \\
\text { but the former appears to } \\
\text { be the most common. }\end{array}$ & $\begin{array}{l}\text { Model by Huberman (1994), } \\
\text { model by Landry et al. (2001), } \\
\text { model by Davis et al. (2007), } \\
\text { model by Majdzadeh et al. (2008), } \\
\text { the CIHR Model of Knowledge } \\
\text { Translation (Canadian Institutes } \\
\text { of Health Research, 2014), the } \\
\text { K2A Framework (Wilson et al., } \\
\text { 2011), the Stetler Model (Stetler, } \\
\text { 2010), the ACE Star Model of } \\
\text { Knowledge Transformation } \\
\text { (Stevens, 2013), the Knowledge- } \\
\text { to-Action Model (Graham et al., } \\
\text { 2006), the Iowa Model (Titler } \\
\text { et al., 1994; Titler et al., 2001), } \\
\text { the Ottawa Model (Logan and } \\
\text { Graham, 1998, 2010), model } \\
\text { by Grol and Wensing (2004), } \\
\text { model by Pronovost et al. (2008), } \\
\text { the Quality Implementation } \\
\text { Framework (Meyers et al., 2012) }\end{array}$ \\
\hline $\begin{array}{l}\text { Determinant } \\
\text { frameworks }\end{array}$ & $\begin{array}{l}\text { Specify types (also known } \\
\text { as classes or domains) } \\
\text { of determinants and } \\
\text { individual determinants, } \\
\text { which act as barriers and } \\
\text { enablers (independent } \\
\text { variables) that influence } \\
\text { implementation outcomes } \\
\text { (dependent variables). } \\
\text { Some frameworks also } \\
\text { specify relationships } \\
\text { between some types } \\
\text { of determinants. The } \\
\text { overarching aim is to } \\
\text { understand and/or } \\
\text { explain influences on } \\
\text { implementation outcomes, } \\
\text { e.g., predicting outcomes } \\
\text { or interpreting outcomes } \\
\text { retrospectively. }\end{array}$ & $\begin{array}{l}\text { i-PARIHS (Harvey and Kitson, } \\
\text { 2016), PARIHS (Kitson et } \\
\text { al., 1998; Rycroft-Malone, } \\
\text { 2010), Active Implementation } \\
\text { Frameworks (Blasé et al., } \\
\text { 2012; Holmes et al., 2012), } \\
\text { Understanding-User-Context } \\
\text { Framework (Jacobson et al., } \\
\text { 2003), Conceptual Model } \\
\text { (Greenhalgh et al., 2005), } \\
\text { framework by Grol et al. (2005), } \\
\text { framework by Cochrane et al. } \\
\text { (2007), framework by Nutley et } \\
\text { al. (2007), Ecological Framework } \\
\text { by Durlak and DuPre (2008), } \\
\text { CFIR (Damschroder et al., 2009), } \\
\text { framework by Gurses et al. (2010), } \\
\text { framework by Ferlie and Shortell } \\
\text { (2001), Theoretical Domains } \\
\text { Framework (Michie et al., 2014) }\end{array}$ \\
\hline
\end{tabular}


Table 1.1 (continued)

\begin{tabular}{|c|c|c|}
\hline Category & Description & Examples \\
\hline Classic theories & $\begin{array}{l}\text { Theories that originate } \\
\text { from fields external to } \\
\text { implementation science, } \\
\text { e.g., psychology, sociology } \\
\text { and organizational theory, } \\
\text { which can be applied to } \\
\text { provide understanding and/ } \\
\text { or explanation of aspects of } \\
\text { implementation. }\end{array}$ & $\begin{array}{l}\text { Theory of Diffusion (Rogers, } \\
\text { 2003), social cognitive theories, } \\
\text { theories concerning cognitive } \\
\text { processes and decision-making, } \\
\text { social networks theories, social } \\
\text { capital theories, communities of } \\
\text { practice, professional theories, } \\
\text { organizational theories }\end{array}$ \\
\hline $\begin{array}{l}\text { Implementation } \\
\text { theories }\end{array}$ & $\begin{array}{l}\text { Theories that have been } \\
\text { developed by implementation } \\
\text { researchers (from scratch } \\
\text { or by adapting existing } \\
\text { theories and concepts) to } \\
\text { provide understanding and/ } \\
\text { or explanation of aspects of } \\
\text { implementation. }\end{array}$ & $\begin{array}{l}\text { Implementation Climate (Klein } \\
\text { and Sorra, 1996), Absorptive } \\
\text { Capacity (Zahra and George, } \\
\text { 2002), Organizational Readiness } \\
\text { (Weiner, 2009), COM-B (Michie } \\
\text { et al., 2011), Normalization } \\
\text { Process Theory (May and Finch, } \\
\text { 2009) }\end{array}$ \\
\hline $\begin{array}{l}\text { Evaluation } \\
\text { frameworks }\end{array}$ & $\begin{array}{l}\text { Specify aspects of } \\
\text { implementation that could } \\
\text { be evaluated to determine } \\
\text { implementation success. }\end{array}$ & $\begin{array}{l}\text { RE-AIM (Glasgow et al., 1999); } \\
\text { PRECEDE-PROCEED (Green } \\
\text { et al., 2005); framework by } \\
\text { Proctor et al. (2010) }\end{array}$ \\
\hline
\end{tabular}

Notes: ACE, Academic Center for Evidence-Based Practice; CFIR, Consolidated Framework for Implementation Research; $C I H R$, Canadian Institutes of Health Research Knowledge; COM-B, Capacity, Opportunities, Motivation, Behaviour; Conceptual Model, Conceptual Model for Considering the Determinants of Diffusion, Dissemination, and Implementation of Innovations in Health Service Delivery and Organization (full title); $K 2 A$, Knowledge-to-Action; (i)-PARIHS, (Integrated)-Promoting Action on Research Implementation in Health Services; PRECEDE-PROCEED, Predisposing, Reinforcing and Enabling Constructs in Educational Diagnosis and Evaluation - Policy, Regulatory, and Organizational Constructs in Educational and Environmental Development; $R E-A I M$, Reach, Effectiveness, Adoption, Implementation, Maintenance.

Early research-to-practice (or knowledge-to-action) models tended to depict rational, linear processes in which research was simply transferred from producers to users. However, subsequent models have highlighted the importance of facilitation to support the process and placed more emphasis on the contexts in which research is implemented and used. Thus, the attention has shifted from a focus on production, diffusion and dissemination of research to various implementation aspects (Nutley et al., 2007).

So-called action (or planned action) models are process models that facilitate implementation by offering practical guidance in the planning 
and execution of implementation endeavours and/or implementation strategies. Action models elucidate important aspects that need to be considered in implementation practice and usually prescribe a number of stages or steps that should be followed in the process of translating research into practice. Action models have been described as active by Graham et al. (2009, p. 185) because they are used 'to guide or cause change'. However, the terminology is not fully consistent, because some of these models are referred to as frameworks; for example, the Knowledgeto-Action Framework (Rycroft-Malone and Bucknall, 2010b).

Many of the action models originate from the nursing-led field of research use or utilization; well-known examples include the Stetler Model (Stetler, 2010), the ACE (Academic Center for Evidence-Based Practice) Star Model of Knowledge Transformation (Stevens, 2013), the Knowledge-to-Action Framework (Graham et al., 2006), the Iowa Model (Titler et al., 1994; Titler et al., 2001) and the Ottawa Model (Logan and Graham, 1998, 2010). There are also numerous examples of similar 'how-to-implement' models that have emerged from other fields, including models developed by Grol and Wensing (2004) and Pronovost et al. (2008), and the Quality Implementation Framework (Meyers et al., 2012), all of which are intended to provide support for planning and managing implementation endeavours.

The how-to-implement models typically emphasize the importance of careful, deliberate planning, especially in the early stages of implementation endeavours. In many ways, they present an ideal view of implementation practice as a process that proceeds stepwise, in an orderly, linear fashion. Still, authors behind most models emphasize that the actual process is not necessarily sequential. Many of the action models mentioned here have been subjected to testing or evaluation, and some have been widely applied in empirical research, underscoring their usefulness (Field et al., 2014; Rycroft-Malone and Bucknall, 2010a).

The process models vary with regard to how they were developed. Models such as the Stetler Model (Stetler, 1994, 2010) and the Iowa Model (Titler et al., 1994; Titler et al., 2001) were based on the originators' own experiences of implementing new practices in various settings (although they were also informed by research and expert opinion). In contrast, models such as the Knowledge-to-Action Framework (Graham et al., 2009) and the Quality Implementation Framework (Meyers et al., 2012) have relied on literature reviews of theories, models, frameworks and individual studies to identify key features of successful implementation endeavours. 


\section{DETERMINANT FRAMEWORKS}

Determinant frameworks describe general types (also referred to as classes or domains) of determinants that are hypothesized or have been found to influence implementation outcomes, for example, health care professionals' behaviour change or adherence to a clinical guideline. Each type of determinant typically comprises a number of individual barriers (hindrances, impediments) and/or enablers (facilitators), which are seen as independent variables that have an impact on implementation outcomes, that is, the dependent variable. Some frameworks also hypothesize relationships between these determinants (e.g., Durlak and DuPre, 2008; Greenhalgh et al., 2005; Gurses et al., 2010), whereas others recognize such relationships without clarifying them (e.g., Cochrane et al., 2007; Damschroder et al., 2009). Information about what influences implementation outcomes is potentially useful for designing and executing implementation strategies that aim to change relevant determinants.

The determinant frameworks do not address how change takes place or any causal mechanisms, underscoring that they should not be considered theories. Many frameworks are multi-level, identifying determinants at different levels, from the individual user or adopter (for example, health care practitioners) to the organization and beyond. Hence, these integrative frameworks recognize that implementation is a multidimensional phenomenon, with multiple interacting influences.

The determinant frameworks were developed in different ways. Many frameworks (e.g., Cochrane et al., 2007; Durlak and DuPre, 2008; Ferlie and Shortell, 2001; Greenhalgh et al., 2005; Grol et al., 2005; Nutley et al., 2007) were developed by synthesizing results from empirical studies of barriers and enablers for implementation success. Other frameworks have relied on existing determinant frameworks and relevant theories in various disciplines, for example, the frameworks by Gurses et al. (2010) and the CFIR (Consolidated Framework for Implementation Research) (Damschroder et al., 2009).

Several frameworks have drawn extensively on the originator's own experiences of implementing new practices. For instance, the Understanding-User-Context Framework (Jacobson et al., 2003) and Active Implementation Frameworks (Blasé et al., 2012) were both based on a combination of literature reviews and the originators' implementation experiences. Meanwhile, PARIHS (Promoting Action on Research Implementation in Health Services) (Kitson et al., 1998; Rycroft-Malone, 2010) emerged from the observation that successful implementation in health care might be premised on three key determinants (characteristics of the evidence, context and facilitation), a proposition that was then 
analysed in four empirical case studies; PARIHS has subsequently undergone substantial research and development work (Rycroft-Malone, 2010) and has been widely applied (Helfrich et al., 2010).

The Theoretical Domains Framework represents another approach to developing determinant frameworks. It was constructed on the basis of a synthesis of 128 constructs related to behaviour change found in 33 behaviour change theories, including many social cognitive theories (Cane et al., 2012). The constructs are sorted into 14 theoretical domains (originally 12 domains): for example, knowledge, skills, intentions, goals, social influences and beliefs about capabilities (Michie et al., 2014). The Theoretical Domains Framework does not specify the causal mechanisms found in the original theories, thus sharing many characteristics with determinant frameworks.

The frameworks are superficially quite disparate, with a broad range of terms, concepts and constructs as well as different outcomes, yet they are quite similar with regard to the general types of determinants they account for. Hence, implementation researchers agree to a large extent on what the main influences on implementation outcomes are, albeit to a lesser extent on which terms that are best used to describe these determinants. Many determinant frameworks account for five types of determinants, as shown in Figure 1.2:

- characteristics of the implementation object;

- influences at the individual health care professional level;

- patient influences;

- collective-level influences;

- effectiveness of implementation strategies used to support implementation.

The arrow in Figure 1.2 represents the implementation outcomes that result from the five types of determinants. The links between the nodes depict the interdependency between the different types of determinants to underscore that they should ideally be assessed holistically, that is, not in isolation of each other. There could be synergistic effects such that two seemingly minor barriers constitute an important obstacle to successful outcomes if they interact or potentially strong facilitators may combine to generate weak effects.

The frameworks describe implementation 'objects' in terms of research, guidelines, interventions, innovations and evidence (that is, research-based knowledge in a broad sense). Outcomes differ correspondingly, from adherence to guidelines and research use, to successful implementation of interventions, innovations, evidence, and so on (that is, the application 


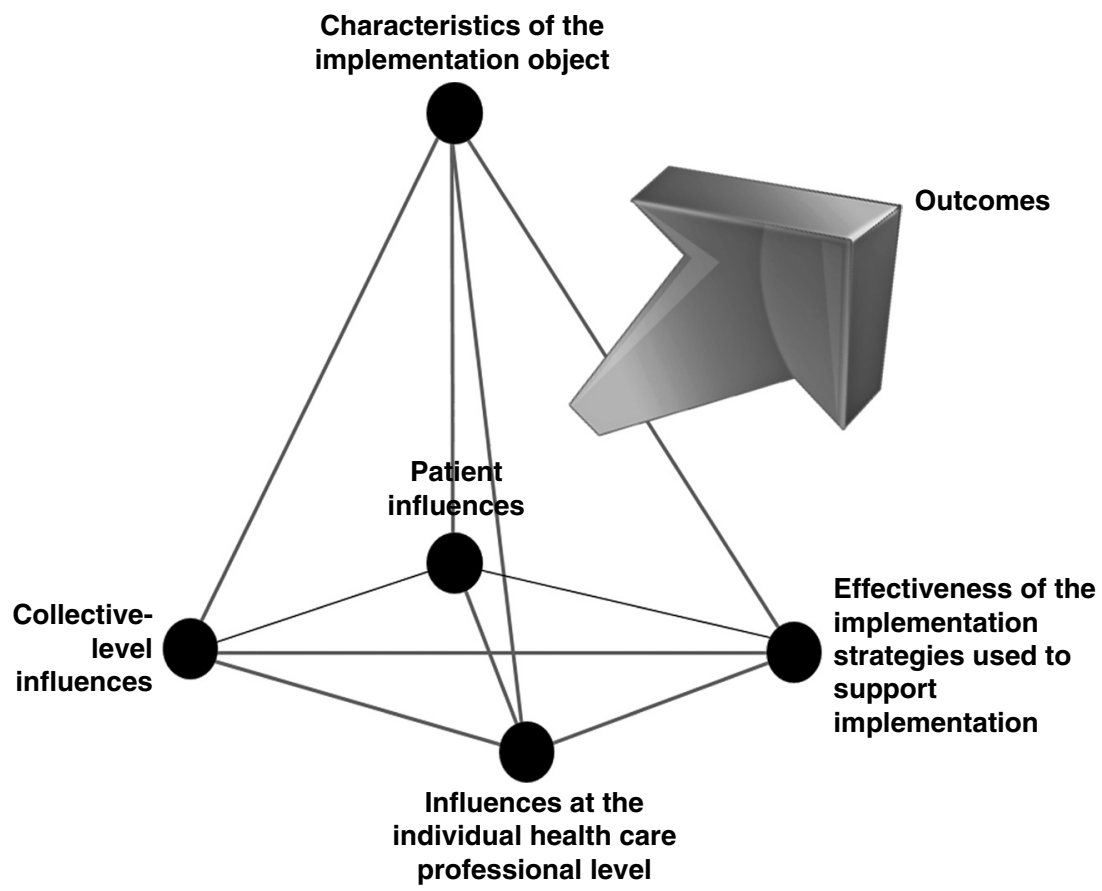

Figure 1.2 Illustrating the interdependent determinants of implementation success

of research-based knowledge in practice). The relevance of the end users (for example, patients, consumers or community populations) of the implemented object is not explicitly addressed in some frameworks (e.g., Fixsen et al., 2005; Greenhalgh et al., 2005; Nutley et al., 2007), suggesting that this is an area where further research is needed for better analysis of how various end users may influence implementation outcomes.

Determinant frameworks imply a systems approach to implementation because they point to multiple levels of influence and acknowledge that there are relationships within and across the levels and different types of determinants. A system can be understood only as an integrated whole, because it is composed of not only the sum of its components but also the relationships among those components (Holmes et al., 2012). However, determinants are often assessed individually in implementation studies (e.g., Broyles et al., 2012; Légaré et al., 2008; Johnson et al., 2010; Verweij et al., 2012), (implicitly) assuming a linear relationship between the determinants and the outcomes and ignoring that individual barriers and enablers may interact in various ways that can be difficult to predict. 
Another issue is whether all relevant barriers and enablers are examined in these studies, which are often based on survey questionnaires, and are thus biased by the researcher's selection of determinants. Surveying the perceived importance of a finite set of predetermined barriers can yield insights into the relative importance of these particular barriers but may overlook factors that independently affect implementation outcomes. Furthermore, there is the issue of whether the barriers and enablers are the actual determinants (that is, whether they have actually been experienced or encountered), and the extent to which they are perceived to exist (that is, they are more hypothetical barriers and enablers). The perceived importance of particular factors may not always correspond with the actual importance.

The context is an integral part of all the determinant frameworks. Described as 'an important but poorly understood mediator of change and innovation in health care organizations' (Dopson and Fitzgerald, 2005, p.79), the context lacks a unifying definition in implementation science (and related fields such as organizational behaviour and quality improvement). Still, context is generally understood as the conditions or surroundings in which something exists or occurs, typically referring to an analytical unit that is higher than the phenomena directly under investigation. The role afforded the context varies from studies (e.g., Ashton et al., 2007; Mohr et al., 2008; Scott et al., 2008; Zardo and Collie, 2014) that essentially view the context in terms of a physical 'environment or setting in which the proposed change is to be implemented' (Kitson et al., 1998, p. 150), to studies (e.g., Ashton et al., 2007; Gabbay, 2004; Nutley et al., 2007) that assume that the context is something more active and dynamic that greatly affects the implementation process and outcomes. Hence, although implementation science researchers agree that the context is a critically important concept for understanding and explaining implementation, there is a lack of consensus regarding how this concept should be interpreted, in what ways the context is manifested, and the means by which contextual influences might be captured in research.

The different types of determinants specified in determinant frameworks can be linked to classic theories. Thus, psychological theories that delineate factors influencing individual behaviour change are relevant for analysing how user or adopter characteristics affect implementation outcomes; whereas organizational theories concerning organizational climate, culture and leadership are more applicable for addressing the influence of the context on implementation outcomes. 


\section{CLASSIC THEORIES}

Implementation researchers are also wont to apply theories from other fields such as psychology, sociology and organizational theory. These theories have been referred to as classic (or classic change) theories, to distinguish them from research-to-practice models (Graham et al., 2009). They might be considered passive in relation to action models because they describe change mechanisms and explain how change occurs without ambitions to actually bring about change.

Psychological behaviour change theories such as the Theory of Reasoned Action (Fishbein and Ajzen, 1975), the Social Cognitive Theory (Bandura, 1977, 1986), the Theory of Interpersonal Behaviour (Triandis, 1980) and the Theory of Planned Behaviour (Ajzen, 2005) have all been widely used in implementation science to study determinants of 'clinical behaviour' change (Nilsen et al., 2012). Theories such as the Cognitive Continuum Theory (Hammond, 1981), the Novice-Expert Theory (Benner, 1984), the Cognitive-Experiential Self-Theory (Epstein, 1994) and habit theories (e.g., Ouellette and Wood, 1998; Verplanken and Aarts, 1999) may also be applicable for analysing cognitive processes involved in clinical decisionmaking and implementing EBP, but they are not as extensively used as the behaviour change theories.

Theories regarding the collective level (such as health care teams) or other aggregate levels are relevant in implementation science; for example, theories concerning professions and communities of practice, as well as theories concerning the relationships between individuals, such as social networks and social capital (Cunningham et al., 2011; Eccles et al., 2009; Estabrooks et al., 2006; Grol and Wensing, 2004; Parchman et al., 2011; Mascia and Cicchetti, 2011). However, their use is not as prevalent as the individual-level theories.

There is increasing interest among implementation researchers in using theories concerning the organizational level because the context of implementation is becoming more widely acknowledged as an important influence on implementation outcomes.

Theories concerning organizational culture, organizational climate, leadership and organizational learning are relevant for understanding and explaining organizational influences on implementation processes (Chaudoir et al., 2013; Durlak and DuPre, 2008; French et al., 2009; Gifford et al., 2007; Grol and Wensing, 2004; Nutley et al., 2007; Meijers et al., 2006; Parmelli et al., 2011; Wallin et al., 2006; Wensing et al., 2006; Yano, 2008). Several organization-level theories might have relevance for implementation science. For instance, Estabrooks et al. (2006) have proposed the use of the Situated Change Theory (Orlikowski, 1996) and the 
Institutional Theory (DiMaggio and Powell, 1991; Scott, 1995), whereas Plsek and Greenhalgh (2001) have suggested the use of complexity science (Waldrop, 1992) for better understanding of organizations. Meanwhile, Grol et al. (2005) have highlighted the relevance of economic theories and theories of innovative organizations. However, despite increased interest in organizational theories, their actual use in empirical implementation studies thus far is relatively limited.

The Theory of Diffusion, as popularized through Rogers's work on the spread of innovations, has also influenced implementation science. The theory's notion of innovation attributes - that is, relative advantage, compatibility, complexity, trialability and observability (Rogers, 2003) has been widely applied in implementation science, both in individual studies (e.g., Aubert and Hamel, 2001; Foy et al., 2002; Völlink et al., 2002) and in determinant frameworks (e.g., Damschroder et al., 2009; Greenhalgh et al., 2005; Gurses et al., 2010), to assess the extent to which the characteristics of the implementation object (for example, a clinical guideline) affect implementation outcomes. Furthermore, the Theory of Diffusion highlights the importance of intermediary actors (opinion leaders, change agents and gatekeepers) for successful adoption and implementation (Rogers, 2003), which is reflected in roles described in numerous implementation determinant frameworks (e.g., Blasé et al., 2012; Rycroft-Malone, 2010) and implementation strategy taxonomies (e.g., Grimshaw et al., 2003; Leeman et al., 2007; Oxman et al., 1995; Walter et al., 2003). The Theory of Diffusion is considered the single most influential theory in the broader field of knowledge utilization of which implementation science is a part (Estabrooks et al., 2008).

\section{IMPLEMENTATION THEORIES}

There are also numerous theories that have been developed or adapted by researchers for potential use in implementation science to achieve enhanced understanding and explanation of certain aspects of implementation. Some of these have been developed by modifying certain features of existing theories or concepts; for example, concerning organizational climate and culture. Examples include theories such as Implementation Climate (Klein and Sorra, 1996), Absorptive Capacity (Zahra and George, 2002) and Organizational Readiness (Weiner, 2009). The adaptation allows researchers to prioritize aspects considered to be most critical to analyse issues related to the how and why of implementation, thus improving the relevance and appropriateness to the particular circumstances at hand. 
COM-B (Capability, Opportunity, Motivation, Behaviour) represents another approach to developing theories that might be applicable in implementation science. This theory began by identifying motivation as a process that energizes and directs behaviour. Capability and opportunity were added as necessary conditions for a volitional behaviour to occur, given sufficient motivation, on the basis of a United States (US) consensus meeting of behavioural theorists and a principle of US criminal law (which considers prerequisites for performance of specified volitional behaviours) (Michie et al., 2011). COM-B posits that capability, opportunity and motivation generate behaviour, which in turn influences the three components. Opportunity and capability can influence motivation, and enacting a behaviour can alter capability, motivation and opportunity (Michie et al., 2014).

Another theory used in implementation science, the Normalization Process Theory (May and Finch, 2009), began life as a model, constructed on the basis of empirical studies of the implementation of new technologies (May et al., 2007). The model was subsequently expanded and developed into a theory as change mechanisms and interrelations between various constructs were delineated (Finch et al., 2013). The theory identifies four determinants of embedding (that is, normalizing) complex interventions in practice - coherence or sense-making, cognitive participation or engagement, collective action and reflexive monitoring - and the relationships between these determinants (Murray et al., 2010).

\section{EVALUATION FRAMEWORKS}

There is a category of frameworks that provides a structure for evaluating implementation endeavours. Two common frameworks that originated in publichealth are RE-AIM (Reach, Effectiveness, Adoption, Implementation, Maintenance) (Glasgow et al., 1999) and PRECEDE-PROCEED (Predisposing, Reinforcing and Enabling Constructs in Educational Diagnosis and Evaluation - Policy, Regulatory, and Organizational Constructs in Educational and Environmental Development) (Green et al., 2005). Both frameworks specify implementation aspects that should be evaluated as part of intervention studies.

Proctor et al. (2010) have developed a framework of implementation outcomes that can be applied to evaluate implementation endeavours. On the basis of a narrative literature review, they propose eight conceptually distinct outcomes for potential evaluation: acceptability, adoption (also referred to as uptake), appropriateness, costs, feasibility, fidelity, penetration (integration of a practice within a specific setting) and sustainability (also referred to as maintenance or institutionalization). 
Although evaluation frameworks may be considered in a category of their own, theories, models and frameworks from the other four categories can also be applied for evaluation purposes because they specify concepts and constructs that may be operationalized and measured. For instance, the Theoretical Domains Framework (e.g., Fleming et al., 2014; Phillips et al., 2015), Normalization Process Theory (McEvoy et al., 2014) and COM-B (e.g., Connell et al., 2015; Praveen et al., 2014) have all been widely used as evaluation frameworks. Furthermore, many theories, models and frameworks have spawned instruments that serve evaluation purposes; for example, tools linked to PARIHS (Estabrooks et al., 2009; McCormack et al., 2009), CFIR (Damschroder and Lowery, 2013) and the Theoretical Domains Framework (Dyson et al., 2013). Other examples include the EBP Implementation Scale, to measure the extent to which EBP is implemented (Melnyk et al., 2008) and the BARRIERS Scale to identify barriers to research use (Kajermo et al., 2010), as well as instruments to operationalize theories such as Implementation Climate (Jacobs et al., 2014) and Organizational Readiness (Gagnon et al., 2011).

\section{CONCLUDING REMARKS}

This chapter proposes a taxonomy of five categories of theories, models and frameworks used in implementation science. These categories are not always recognized as separate types of approaches in the literature. For instance, systematic reviews and overviews by Graham and Tetroe (2007), Mitchell et al. (2010), Flottorp et al. (2013), Meyers et al. (2012) and Tabak et al. (2012) have not distinguished between process models, determinant frameworks or classic theories because they all deal with factors believed or found to have an impact on implementation processes and outcomes. However, what matters most is not how an individual approach is labelled; it is important to recognize that these theories, models and frameworks differ in terms of their assumptions, aims and other characteristics, which have implications for their use.

There is considerable overlap between some of the categories. Thus, determinant frameworks, classic theories and implementation theories can also help to guide implementation practice (that is, functioning as action models), because they identify potential barriers and enablers that might be important to address when undertaking an implementation endeavour. They can also be used for evaluation because they describe aspects that might be important to evaluate. A framework such as the Active Implementation Frameworks (Holmes et al., 2012) appears to have 
a dual aim of providing hands-on support to implement something and identifying determinants of this implementation that should be analysed. Somewhat similarly, PARIHS (Kitson et al., 1998) can be used by 'anyone either attempting to get evidence into practice, or anyone who is researching or trying to better understand implementation processes and influences' (Rycroft-Malone, 2010, p.120), suggesting that it has ambitions that go beyond its primary function as a determinant framework.

Despite the overlap between different theories, models and frameworks used in implementation science, knowledge about the three overarching aims and five categories of theoretical approaches is important to identify and select relevant approaches in various situations. Most determinant frameworks provide limited 'how-to' support for carrying out implementation endeavours, because the determinants may be too generic to provide sufficient detail for guiding users through an implementation process. Although the relevance of addressing barriers and enablers to translating research into practice is mentioned in many process models, these models do not identify or systematically structure specific determinants associated with implementation success. Another key difference is that process models recognize a temporal sequence of implementation endeavours, whereas determinant frameworks do not explicitly take a process perspective of implementation because the determinants typically relate to implementation as a whole.

Selecting an appropriate theory, model or framework often represents a considerable challenge for implementation researchers. Choosing one approach means placing weight on some aspects (for example, certain causal factors) at the expense of others, thus offering only partial understanding. Combining the merits of multiple theoretical approaches may offer more complete understanding and explanation, yet such combinations may mask contrasting assumptions regarding key issues. For instance, are people driven primarily by their individual beliefs and motivation, or does a pervasive organizational culture impose norms and values that regulate how people behave and make individual characteristics relatively unimportant? Is a particular behaviour primarily influenced by reflective thought processes, or is it an automatically enacted habit? Furthermore, different approaches may require different methods based on different epistemological and ontological assumptions.

Although the use of theories, models and frameworks has many advocates in implementation science, there have also been critics (Bhattacharyya et al., 2006; Oxman et al., 2005), who have argued that theory is not necessarily better than common sense for guiding implementation. Common sense has been defined as a group's shared tacit knowledge concerning 
a phenomenon (Fletcher, 1984). One could argue that common sense about how or why something works (or does not) also constitutes a theory, albeit an informal and non-codified one. In either case, empirical research is needed to study how and the extent to which the use of implementation theories, models and frameworks contributes to more effective implementation and under what contextual conditions or circumstances they apply (and do not apply). It is also important to explore how the current theoretical approaches can be further developed to better address implementation challenges. Hence, both inductive construction of theory and deductive application of theory are needed.

The use of theory does not necessarily yield more effective implementation than using common sense, yet there are certain advantages to applying formal theory over common sense (that is, informal theory). Theories are explicit and open to question and examination; common sense usually consists of implicit assumptions, beliefs and ways of thinking and is therefore more difficult to challenge. If deductions from a theory are incorrect, the theory can be adapted, extended or abandoned. Theories are more consistent with existing facts than common sense, which typically means that a hypothesis based on an established theory is a more educated guess than one based on common sense. Furthermore, theories give individual facts a meaningful context and contribute towards building an integrated body of knowledge, whereas common sense is more likely to produce isolated facts (Cacioppo, 2004; Fletcher, 1984).

On the other hand, theory may serve as blinkers, as suggested by Kuhn (1970) and Greenwald et al. (1986), causing us to ignore problems that do not fit into existing theories, models and frameworks or hindering us from seeing known problems in new ways. Theorizing about implementation should therefore not be an abstract academic exercise unconnected with the real world of implementation practice. In the words of Immanuel Kant, 'Experience without theory is blind, but theory without experience is mere intellectual play.'

\section{ACKNOWLEDGEMENTS}

I am grateful to Bianca Albers, Susanne Bernhardsson, Dean L. Fixsen, Karen Grimmer, Ursula Reichenpfader and Kerstin Roback for constructive comments on drafts of this chapter. Also, thanks are due to Margit Neher, Justin Presseau and Jeanette Wassar Kirk for their input. 


\section{REFERENCES}

Ajzen, I. (2005) Attitudes, Personality and Behavior. Maidenhead: Open University Press.

Ashton, C.M., Khan, M.M., Johnson, M.L., Walder, A., Stanberry, E., et al. (2007) A quasi-experimental test of an intervention to increase the use of thiazide-based treatment regimens for people with hypertension. Implementation Science 2, 5.

Aubert, B.A., Hamel, G. (2001) Adoption of smart cards in the medical sector: the Canadian experience. Social Science and Medicine 53, 879-894.

Bandura, A. (1977) Self-efficacy: toward a unifying theory of behavioral change. Psychological Review 84, 191-215.

Bandura, A. (1986) Social Foundations of Thought and Action: A Social Cognitive Theory. Englewood Cliffs, NJ: Prentice Hall.

Benner, P.E. (1984) From Novice to Expert: Excellence and Power in Clinical Nursing Practice. Menlo Park, CA: Addison-Wesley.

Bhattacharyya, O., Reeves, S., Garfinkel, S., Zwarenstein, M. (2006) Designing theoreticallyinformed implementation interventions: fine in theory, but evidence of effectiveness in practice is needed. Implementation Science 1, 5 .

Blasé, K.A., Van Dyke, M., Fixsen, D.L., Bailey, F.W. (2012) Implementation science: key concepts, themes and evidence for practitioners in educational psychology. In: Kelly, B., Perkins, D.F. (eds), Handbook of Implementation Science for Psychology in Education. Cambridge: Cambridge University Press, pp. 13-34.

Bluedorn, A.C., Evered, R.D. (1980) Middle range theory and the strategies of theory construction. In: Pinder, C.C., Moore, L.F. (eds), Middle Range Theory and the Study of Organizations. Boston, MA: Martinus Nijhoff, pp. 19-32.

Brownson, R.C., Colditz, G.A., Proctor, E.K. (2012) Dissemination and Implementation Research in Health: Translating Science to Practice. Oxford: Oxford University Press.

Broyles, L., Rodriguez, K.L., Kraemer, K.L., Sevick, M., Price, P.A., Gordon, A.J. (2012) A qualitative study of anticipated barriers and facilitators to the implementation of nurse-delivered alcohol screening, brief intervention, and referral to treatment for hospitalized patients in a Veterans Affairs medical center. Addiction Science and Clinical Practice, 7, 7.

Bunge, M. (1967) Scientific Research 1 (The Search for System). Berlin: Springer.

Cacioppo, J.T. (2004) Common sense, intuition, and theory in personality and social psychology. Personality and Social Psychology Review 8, 114-122.

Cairney, P. (2012) Understanding Public Policy: Theories and Issues. Basingstoke: Palgrave Macmillan.

Canadian Institutes of Health Research (CIHR) (2014) About knowledge translation. http:// www.cihr-irsc.gc.ca/e/29418.html. Accessed 18 December 2014.

Cane, J., O'Connor, D., Michie, S. (2012) Validation of the theoretical domains framework for use in behaviour change and implementation research. Implementation Science 7, 37.

Carpiano, R.M. (2006). A guide and glossary on postpositivist theory building for population health. Journal of Epidemiology and Community Health 60, 564-570.

Chaudoir, S.R., Dugan, A.G., Barr, C.H. (2013) Measuring factors affecting implementation of health innovations: a systematic review of structural, organizational, provider, patient, and innovation level measures. Implementation Science 8, 22.

Cochrane, L.J., Olson, C.A., Murray, S., Dupuis, M., Tooman, T., Hayes, S. (2007) Gaps between knowing and doing: understanding and assessing the barriers to optimal health care. Journal of Continuing Education in the Health Professions, 27, 94-102.

Connell, L.A., McMahon, N.E., Redfern, J., Watkins, C.L., Eng, J.J. (2015) Development of a behaviour change intervention to increase upper limb exercise in stroke rehabilitation. Implementation Science 10, 34.

Cunningham, F.C., Ranmuthugala, G., Plumb, J., Georgiou, A., Westbrook, J.I., Braithwaite, J. (2011) Health professional networks as a vector for improving healthcare quality and safety: a systematic review. BMJ Quality and Safety 21, 239-249.

Damschroder, L.J., Aron, D.C., Keith, R.E., Kirsh, S.R., Alexander, J.A., Lowery, J.C. 
(2009) Fostering implementation of health services research findings into practice: a consolidated framework for advancing implementation science. Implementation Science 4, 50.

Damschroder, L.J., Lowery, J.C. (2013) Evaluation of a large-scale weight management program using the consolidated framework for implementation research (CFIR). Imple mentation Science 8, 51.

Davies, P., Walker, A., Grimshaw, J. (2003) Theories of behavior change in studies of guideline implementation. Proceedings of the British Psychological Society 11, 120.

Davis, S.M., Peterson, J.C., Helfrich, C.D., Cunningham-Sabo, L. (2007) Introduction and conceptual model for utilization of prevention research. American Journal of Preventive Medicine 33(1 Suppl), S1-S5.

DiMaggio, P.J., Powell, W.W. (1991) The New Institutionalism and Organizational Analysis. Chicago, IL: University of Chicago Press.

Dopson, S., Fitzgerald, L. (2005) The active role of context. In: Dopson, S., Fitzgerald, L. (eds), Knowledge to Action? Evidence-Based Health Care in Context. New York: Oxford University Press, pp. 79-103.

Dubin, R. (1969) Theory Building. New York: Free Press.

Durlak, J.A., DuPre, E.P. (2008) Implementation matters: a review of research on the influence of implementation on program outcomes and the factors affecting implementation. American Journal of Community Psychology 41, 327-350.

Dyson, J., Lawton, R., Jackson, C., Cheater, F. (2013) Development of a theory-based instrument to identify barriers and levers to best hand hygiene practice among healthcare practitioners. Implementation Science 8, 111.

Eccles, M.P., Grimshaw, J., Walker, A., Johnston, M., Pitts, N. (2005) Changing the behavior of healthcare professionals: the use of theory in promoting the uptake of research findings. Journal of Clinical Epidemiology 58, 107-112.

Eccles, M.P., Hrisos, S., Francis, J.J., Steen, N., Bosch, M., Johnston, M. (2009) Can the collective intentions of individual professionals within healthcare teams predict the team's performance: developing methods and theory. Implementation Science 4, 24.

Epstein, S. (1994) Integration of the cognitive and the psychodynamic unconscious. American Psychologist 49, 709-724.

Estabrooks, C.A., Derksen, L., Winther, C., Lavis, J.N., Scott, S.D., Wallin, L., ProfettoMcGrath, J. (2008) The intellectual structure and substance of the knowledge utilization field: a longitudinal author co-citation analysis, 1945 to 2004. Implementation Science 3, 49.

Estabrooks, C.A., Squires, J.E., Cummings, G.G., Birdsell, J.M., Norton, P.G. (2009) Development and assessment of the Alberta Context Tool. BMC Health Services Research 9, 234.

Estabrooks, C.A., Thompson, D.S., Lovely, J.J., Hofmeyer, A. (2006) A guide to knowledge translation theory. Journal of Continuing Education in the Health Professions 26, 25-36.

Ferlie, E.B., Shortell, S.M. (2001) Improving the quality of health care in the United Kingdom and the United States: a framework for change. Milbank Quarterly 79, 281-315.

Field, B., Booth, A., Ilott, I., Gerrish, K. (2014) Using the Knowledge to Action Framework in practice: a citation analysis and systematic review. Implementation Science 9, 172.

Finch, T.L., Rapley, T., Girling, M., Mair, F.S., Murray, E., et al. (2013) Improving the normalization of complex interventions: measure development based on normalization process theory (NoMAD): study protocol. Implementation Science 8, 43.

Fishbein, M., Ajzen, I. (1975) Belief, Attitude, Intention, and Behaviour. New York: John Wiley.

Fixsen, D.L., Naoom, S.F., Blasé, K.A., Friedman, R.M., Wallace, F. (2005) Implementation Research: A Synthesis of the Literature. Tampa, FL: National Implementation Research Network.

Fleming, A., Bradley, C., Cullinan, S., Byrne, S. (2014) Antibiotic prescribing in long-term care facilities: a qualitative, multidisciplinary investigation. BMJ Open 4, e006442.

Fletcher, G.J. (1984) Psychology and common sense. American Psychologist 39, $203-213$.

Flottorp, S.A., Oxman, A.D., Krause, J., Musila, N.R., Wensing, M., et al. (2013) A checklist for identifying determinants of practice: a systematic review and synthesis of 
frameworks and taxonomies of factors that prevent or enable improvements in healthcare professional practice. Implementation Science 8, 35.

Foy, R., Maclennan, G., Grimshaw, J., Penney, G., Campbell, M., Grol, R. (2002) Attributes of clinical recommendations that influence change in practice following audit and feedback. Journal of Clinical Epidemiology 55, 717-722.

Frankfort-Nachmias, C., Nachmias, D. (1996) Research Methods in the Social Sciences. London: Arnold.

French, B., Thomas, L.H., Baker, P., Burton, C.R., Pennington, L., Roddam, H. (2009) What can management theories offer evidence-based practice? A comparative analysis of measurement tools for organisational context. Implementation Science 4, 28.

Gabbay, J. (2004) Evidence based guidelines or collectively constructed 'mindlines?' Ethnographic study of knowledge management in primary care. BMJ 329, 1013.

Gagnon, M., Labarthe, J., Légaré, F., Ouimet, M., Estabrooks, C.A., et al. (2011) Measuring organizational readiness for knowledge translation in chronic care. Implementation Science 6, 72.

Gifford, W., Davies, B., Edwards, N., Griffin, P., Lybanon, V. (2007) Managerial leadership for nurses' use of research evidence: an integrative review of the literature. Worldviews on Evidence-Based Nursing 4, 126-145.

Glasgow, R.E., Vogt, T.M., Boles, S.M. (1999) Evaluating the public health impact of health promotion interventions: the RE-AIM framework. American Journal of Public Health 89, $1322-1327$.

Godin, G., Bélanger-Gravel, A., Eccles, M., Grimshaw, J. (2008) Healthcare professionals' intentions and behaviours: a systematic review of studies based on social cognitive theories. Implementation Science 3, 36.

Graham, I.D., Logan, J., Harrison, M.B., Straus, S.E., Tetroe, J., et al. (2006) Lost in knowledge translation: time for a map? Journal of Continuing Education in the Health Professions 26, 13-24.

Graham, I.D., Tetroe, J. (2007) Some theoretical underpinnings of knowledge translation. Academic Emergency Medicine 14, 936-941.

Graham, I.D., Tetroe, J., KT Theories Group (2009) Planned action theories. In: Straus, S.E., Tetroe, J., Graham, I.D. (eds), Knowledge Translation in Health Care: Moving from Evidence to Practice. Chichester: Wiley-Blackwell/BMJ, pp. 185-195.

Green, L.W., Kreuter, M.W., Green, L.W. (2005) Health Program Planning: An Educational and Ecological Approach. New York: McGraw-Hill.

Greenhalgh, T., Robert, G., Bate, P., Macfarlane, F., Kyriakidou, O. (2005) Diffusion of Innovations in Service Organisations: A Systematic Literature Review. Malden, MA: Blackwell.

Greenwald, A.G., Pratkanis, A.R., Leippe, M.R., Baumgardner, M.H. (1986) Under what conditions does theory obstruct research progress? Psychological Review 93, 216-229.

Grimshaw, J., McAuley, L.M., Bero, L.A., Grilli, R., Oxman, A.D., et al. (2003) Systematic reviews of effectiveness of quality improvement strategies and programmes. Quality and Safety in Health Care 12, 298-303.

Grol, R., Wensing, M. (2004) What drives change? Barriers to and incentives for achieving evidence-based practice. Medical Journal of Australia 180, S57-S60.

Grol, R., Wensing, M., Eccles, M. (2005) Improving Patient Care: The Implementation of Change in Clinical Practice. Edinburgh: Elsevier Butterworth Heinemann.

Gurses, A.P., Marsteller, J.A., Ozok, A.A., Xiao, Y., Owens, S., Pronovost, P.J. (2010) Using an interdisciplinary approach to identify factors that affect clinicians' compliance with evidence-based guidelines. Critical Care Medicine 38(8 Suppl), S282-S291.

Hammond, K.R. (1981) Principles of Organization in Intuitive and Analytical Cognition. Ft Belvoir, VA: Defense Technical Information Center.

Harvey, G., Kitson. A. (2016) PARIHS revisited: from heuristic to integrated framework for the successful implementation of knowledge into practice. Implementation Science 11, 33.

Helfrich, C.D., Damschroder, L.J., Hagedorn, H.J., Daggett, G.S., Sahay, A., et al. (2010) 
A critical synthesis of literature on the promoting action on research implementation in health services (PARIHS) framework. Implementation Science 5, 82.

Holmes, B.J., Finegood, D.T., Riley, B.L., Best, A. (2012) Systems thinking in dissemination and implementation research. In: Brownson, R.C., Colditz, G.A., Proctor, E.K. (eds), Dissemination and Implementation Research in Health. Oxford: Oxford University Press, pp. 192-212.

Huberman, M. (1994) Research utilization: the state of the art. Knowledge and Policy 7, $13-33$.

Hunt, S.D. (1991) Modern Marketing Theory: Critical Issues in the Philosophy of Marketing Science. Cincinnati, OH: South-Western Publishing.

ICEBeRG. (2006) Designing theoretically-informed implementation interventions. Implementation Science 1, 4.

Jacobs, S.R., Weiner, B.J., Bunger, A.C. (2014) Context matters: measuring implementation climate among individuals and groups. Implementation Science 9, 46.

Jacobson, N., Butterill, D., Goering, P. (2003) Development of a framework for knowledge translation: understanding user context. Journal of Health Services Research Policy 8, 94-99.

Johnson, M., Jackson, R., Guillaume, L., Meier, P., Goyder, E. (2010) Barriers and facilitators to implementing screening and brief intervention for alcohol misuse: a systematic review of qualitative evidence. Journal of Public Health 33, 412-421.

Kajermo, K.N., Boström, A., Thompson, D.S., Hutchinson, A.M., Estabrooks, C.A., Wallin, L. (2010) The BARRIERS scale - the barriers to research utilization scale: a systematic review. Implementation Science 5, 32 .

Kitson, A.L., Harvey, G., McCormack, B. (1998) Enabling the implementation of evidence based practice: a conceptual framework. Quality and Safety in Health Care 7, 149-158.

Kitson, A.L., Rycroft-Malone, J., Harvey, G., McCormack, B., Seers, K., Titchen, A. (2008) Evaluating the successful implementation of evidence into practice using the PARiHS framework: theoretical and practical challenges. Implementation Science 3, 1.

Klein, K.J., Sorra, J.S. (1996) The challenge of innovation implementation. Academy of Management Review 21, 1055-1080.

Kuhn, T.S. (1970) The Structure of Scientific Revolutions. Chicago, IL: University of Chicago Press.

Landry, R., Amara, N., Lamari, M. (2001) Climbing the ladder of research utilization: evidence from social science research. Science Communication 22, 396-422.

Leeman, J., Baernholdt, M., Sandelowski, M. (2007) Developing a theory-based taxonomy of methods for implementing change in practice. Journal of Advanced Nursing 58, 191-200.

Légaré, F., Ratté, S., Gravel, K., Graham, I.D. (2008) Barriers and facilitators to implementing shared decision-making in clinical practice: update of a systematic review of health professionals' perceptions. Patient Education and Counseling 73, 526-535.

Logan, J., Graham, I.D. (1998) Toward a comprehensive interdisciplinary model of health care research use. Science Communication 20, 227-246.

Logan, J., Graham, I. (2010) The Ottawa Model of research use. In: Rycroft-Malone, J., Bucknall, T. (eds), Models and Frameworks for Implementing Evidence-Based Practice: Linking Evidence to Action. Chichester: Wiley-Blackwell, pp. 83-108.

Majdzadeh, R., Sadighi, J., Nejat, S., Mahani, A.S., Gholami, J. (2008) Knowledge translation for research utilization: design of a knowledge translation model at Tehran University of Medical Sciences. Journal of Continuing Education in the Health Professions $28,270-277$.

Martinez, R.G., Lewis, C.C., Weiner, B.J. (2014) Instrumentation issues in implementation science. Implementation Science 9, 118.

Mascia, D., Cicchetti, A. (2011) Physician social capital and the reported adoption of evidence-based medicine: exploring the role of structural holes. Social Science and Medicine 72, 798-805.

May, C., Finch, T. (2009) Implementing, embedding, and integrating practices: an outline of normalization process theory. Sociology 43, 535-554.

May, C., Finch, T., Mair, F., Ballini, L., Dowrick, C., et al. (2007) Understanding the 
implementation of complex interventions in health care: the normalization process model. BMC Health Services Research 7, 148.

McCormack, B., McCarthy, G., Wright, J., Coffey, A. (2009) Development and testing of the Context Assessment Index (CAI). Worldviews on Evidence-Based Nursing 6, 27-35.

McEvoy, R., Ballini, L., Maltoni, S., O'Donnell, C.A., Mair, F.S., Macfarlane, A. (2014) A qualitative systematic review of studies using the normalization process theory to research implementation processes. Implementation Science 9, 2.

Meijers, J.M., Janssen, M.A., Cummings, G.G., Wallin, L., Estabrooks, C.A., Halfens, R.Y. (2006) Assessing the relationships between contextual factors and research utilization in nursing: systematic literature review. Journal of Advanced Nursing 55, 622-635.

Melnyk, B.M., Fineout-Overholt, E., Mays, M.Z. (2008) The Evidence-Based Practice Beliefs and Implementation Scales: psychometric properties of two new instruments. Worldviews on Evidence-Based Nursing 5, 208-216.

Meyers, D.C., Durlak, J.A., Wandersman, A. (2012) The Quality Implementation Framework: a synthesis of critical steps in the implementation process. American Journal of Community Psychology 50, 462-480.

Michie, S., Atkins, L., West, R. (2014) The Behaviour Change Wheel: A Guide to Designing Interventions. London: Silverback.

Michie, S., Johnston, M., Abraham, C., Lawton, R., Parker, D., Walker, A. (2005) Making psychological theory useful for implementing evidence based practice: a consensus approach. Quality and Safety in Health Care 14, 26-33.

Michie, S., Stralen, M.M., West, R. (2011) The behaviour change wheel: a new method for characterising and designing behaviour change interventions. Implementation Science 6, 42.

Mitchell, S.A., Fisher, C.A., Hastings, C.E., Silverman, L.B., Wallen, G.R. (2010) A thematic analysis of theoretical models for translational science in nursing: mapping the field. Nursing Outlook 58, 287-300.

Mohr, D.C., Lukas, C.V., Meterko, M. (2008) Predicting healthcare employees' participation in an office redesign program: attitudes, norms and behavioral control. Implementation Science 3, 47.

Murray, E., Treweek, S., Pope, C., Macfarlane, A., Ballini, L., et al. (2010) Normalisation process theory: a framework for developing, evaluating and implementing complex interventions. BMC Medicine 8, 63.

Nilsen, P., Roback, K., Broström, A., Ellström, P. (2012) Creatures of habit: accounting for the role of habit in implementation research on clinical behaviour change. Implementation Science 7, 53.

Nutley, S.M., Walter, I., Davies, H.T. (2007) Using Evidence: How Research Can Inform Public Services. Bristol: Policy Press.

Orlikowski, W.J. (1996) Improvising organizational transformation over time: a situated change perspective. Information Systems Research 7, 63-92.

Ouellette, J.A., Wood, W. (1998) Habit and intention in everyday life: the multiple processes by which past behavior predicts future behavior. Psychological Bulletin 124, 54-74.

Oxman, A.D., Fretheim, A., Flottorp, S. (2005) The OFF theory of research utilization. Journal of Clinical Epidemiology 58, 113-116.

Oxman, A.D., Thomson, M.A., Davis, D.A., Haynes, R.B. (1995) No magic bullets: a systematic review of 102 trials of interventions to improve professional practice. CMAJ $153,1423-1431$.

Parchman, M.L., Scoglio, C.M., Schumm, P. (2011) Understanding the implementation of evidence-based care: a structural network approach. Implementation Science 6, 14.

Parmelli, E., Flodgren, G., Beyer, F., Baillie, N., Schaafsma, M.E., Eccles, M.P. (2011) The effectiveness of strategies to change organisational culture to improve healthcare performance: a systematic review. Implementation Science 6, 33.

Phillips, C.J., Marshall, A.P., Chaves, N.J., Lin, I.B., Loy, C.T., et al. (2015) Experiences of using Theoretical Domains Framework across diverse clinical environments: a qualitative study. Journal of Multidisciplinary Healthcare 8, 139-146. 
Plsek, P.E., Greenhalgh, T. (2001) Complexity science: the challenge of complexity in health care. $B M J 323,625-628$.

Praveen, D., Patel, A., Raghu, A., Clifford, G.D., Maulik, P.K., et al. (2014) SMARTHealth India: development and field evaluation of a mobile clinical decision support system for cardiovascular diseases in rural India. JMIR MHealth and UHealth 2, e54.

Proctor, E., Silmere, H., Raghavan, R., Hovmand, P., Aarons, G., et al. (2010) Outcomes for implementation research: conceptual distinctions, measurement challenges, and research agenda. Administration and Policy in Mental Health and Mental Health Services Research $38,65-76$.

Pronovost, P.J., Berenholtz, S.M., Needham, D.M. (2008) Translating evidence into practice: a model for large scale knowledge translation. $B M J 337$, a1714.

Reynolds, P.D. (1971) A Primer in Theory Construction. Indianapolis, IN: Bobbs-Merrill.

Rogers, E.M. (2003) Diffusion of Innovations, 5th edn. New York: Free Press.

Rycroft-Malone, J. (2010) Promoting Action on Research Implementation in Health Services (PARIHS). In: Rycroft-Malone, J., Bucknall, T. (eds), Models and Frameworks for Implementing Evidence-Based Practice: Linking Evidence to Action. Chichester: WileyBlackwell, pp. 109-136.

Rycroft-Malone, J., Bucknall, T. (2010a) Theory, frameworks, and models: laying down the groundwork. In: Rycroft-Malone, J., Bucknall, T. (eds), Models and Frameworks for Implementing Evidence-Based Practice: Linking Evidence to Action. Chichester: WileyBlackwell, pp. 23-50.

Rycroft-Malone, J., Bucknall, T. (2010b) Analysis and synthesis of models and frameworks. In: Rycroft-Malone, J., Bucknall, T. (eds), Models and Frameworks for Implementing Evidence-Based Practice: Linking Evidence to Action. Chichester: Wiley-Blackwell, pp. 223-245.

Rycroft-Malone, J., Bucknall, T. (2010c) Models and Frameworks for Implementing EvidenceBased Practice: Linking Evidence to Action. Chichester: Wiley-Blackwell.

Sabatier, P.A. (1999) Theories of the Policy Process. Boulder, CO: Westview Press.

Sales, A., Smith, J., Curran, G., Kochevar, L. (2006) Models, strategies, and tools: theory in implementing evidence-based findings into health care practice. Journal of General Internal Medicine 21(Suppl 2), S43-S49.

Scott, S.D., Plotnikoff, R.C., Karunamuni, N., Bize, R., Rodgers, W. (2008) Factors influencing the adoption of an innovation: an examination of the uptake of the Canadian Heart Health Kit (HHK). Implementation Science 3, 41.

Scott, W.R. (1995) Institutions and Organizations. Thousand Oaks, CA: SAGE.

Stetler, C.B. (1994) Refinement of the Stetler/Marram model for application of research findings to practice. Nursing Outlook 42, 15-25.

Stetler, C.B. (2010) Stetler model. In: Rycroft-Malone, J., Bucknall, T. (eds), Models and Frameworks for Implementing Evidence-Based Practice: Linking Evidence to Action. Chichester: Wiley-Blackwell, pp. 51-82.

Stevens, K.R. (2013) The impact of evidence-based practice in nursing and the next big ideas. Online Journal of Issues in Nursing 18(2), 4.

Straus, S.E., Tetroe, J., Graham, I.D. (2009) Knowledge Translation in Health Care: Moving from Evidence to Practice. Chichester: Wiley-Blackwell/BMJ.

Tabak, R.G., Khoong, E.C., Chambers, D.A., Brownson, R.C. (2012) Bridging research and practice: models for dissemination and implementation research. American Journal of Preventive Medicine 43, 337-350.

Titler, M.G., Kleiber, C., Steelman, V., Goode, C., Rakel, B., et al. (1994) Infusing research into practice to promote quality care. Nursing Research 43, 307-313.

Titler, M.G., Kleiber, C., Steelman, V.J., Rakel, B.A., Budreau, G., et al. (2001) The Iowa Model of evidence-based practice to promote quality care. Critical Care Nursing Clinics of North America 13, 497-509.

Triandis, H.C. (1980) Values, attitudes, and interpersonal behaviour. In: Page, M.M., Howe, H.E. (eds), Nebraska Symposium on Motivation, 1979: Beliefs, Attitudes and Values. Lincoln, NE: University of Nebraska Press, pp. 195-259. 
Verplanken, B., Aarts, H. (1999) Habit, attitude, and planned behaviour: is habit an empty construct or an interesting case of goal-directed automaticity? European Review of Social Psychology 10, 101-134.

Verweij, L.M., Proper, K.I., Leffelaar, E.R., Weel, A.N., Nauta, A.P., et al. (2012) Barriers and facilitators to implementation of an occupational health guideline aimed at preventing weight gain among employees in the Netherlands. Journal of Occupational and Environmental Medicine 54, 954-960.

Völlink, T., Meertens, R., Midden, C.J. (2002) Innovating 'diffusion of innovation' theory: innovation characteristics and the intention of utility companies to adopt energy conservation interventions. Journal of Environmental Psychology 22, 333-344.

Wacker, J. (1998) A definition of theory: research guidelines for different theory-building research methods in operations management. Journal of Operations Management 16, 361-385.

Waldrop, M.M. (1992) Complexity: The Emerging Science at the Edge of Order and Chaos. New York: Simon \& Schuster.

Wallin, L., Ewald, U., Wikblad, K., Scott-Findlay, S., Arnetz, B.B. (2006) Understanding work contextual factors: a short-cut to evidence-based practice? Worldviews on EvidenceBased Nursing 3, 153-164.

Walter, I., Nutley, S.M., Davies, H.T.O. (2003) Developing a taxonomy of interventions used to increase the impact of research. Discussion Paper 3. St Andrews: Research Unit for Research Utilisation, University of St Andrews.

Weiner, B.J. (2009) A theory of organizational readiness for change. Implementation Science 4,67 .

Wensing, M., Wollersheim, H., Grol, R. (2006) Organizational interventions to implement improvements in patient care: a structured review of reviews. Implementation Science 1, 2.

Wilson, K.M., Brady, T.J., Lesesne, C., on behalf of the NCCDPHP Work Group on Translation (2011) An organizing framework for translation in public health: the knowledge to action framework. Preventing Chronic Disease 8, A46.

Yano, E.M. (2008) The role of organizational research in implementing evidence-based practice: QUERI Series. Implementation Science 3, 29.

Zahra, S.A., George, G. (2002) Absorptive capacity: a review, reconceptualization, and extension. Academy of Management Review 27, 185-203.

Zardo, P., Collie, A. (2014) Predicting research use in a public health policy environment: results of a logistic regression analysis. Implementation Science 9, 142. 